\title{
A propósito de desconcertos e travessias ${ }^{1}$
}

\author{
Marcio de F. Giovannetti ${ }^{2}$
}

\author{
“A tradição não é o culto das cinzas, mas a \\ preservação do fogo" \\ (Gustav Mahler)
}

1.

Não há língua viva que não sofra, ao longo de sua existência e consequentemente de seu uso, deslocamentos e deslizamentos semânticos, de significado. Exemplar neste sentido é a palavra concerto e, portanto, desconcerto, sua derivada. Derivando da palavra latina CERTARE que significa disputar, desunir ela foi, ao longo dos séculos, adquirindo exatamente o sentido contrário, isto é, com harmonia. Daí seu deslizamento, no século XVII e que perdura até hoje para o sentido de uma harmonização de vários instrumentos musicais: um concerto musical é exatamente o contrário de uma desunião. Portanto, foi necessário a introdução do prefixo DES- desconcerto- para a língua portuguesa recuperar o sentido original de concerto. Se nós, psicanalistas, estamos sempre às voltas com a língua viva, a nossa e a de nossos pacientes, não há forma de manter o espírito original da psicanálise, aquele que rompe com a ordem estabelecida, se não às custas de um estado de desconcerto constante em nossa clínica. Falar, portanto, do analista desconcertado é falar e pensar o analista em seu trabalho diário às voltas com a escuta da palavra- ou como escreveu Greencom o discurso vivo de cada um de seus pacientes. O que implica estar atento às cesuras e aos deslizamentos que inevitavelmente ocorrem no interior mesmo de cada fala no momento histórico específico de sua enunciação. Cada palavra é, ao mesmo tempo, a palavra nova e a palavra antiga, aquela que foi articulada num momento outro, pretérito, daquele que fala.

\section{2.}

\footnotetext{
${ }^{1}$ Este trabalho é a plenária do eixo "O analista desconcertado", apresentada no I Simpósio Bienal "O mesmo, o outro: Psicanálise em movimento" eixo "O analista desconcertado: mal estar e cínica" da Sociedade Brasileira de Psicanálise de São Paulo.

${ }^{2}$ Analista didata e ex-presidente da SBPSP, membro da Task Force on Representaion da IPA.
} 
Em "Inibição, Sintoma e Angústia", Freud nos alertou a respeito da continuidade da vida intra e extra uterina, muito maior do que a impressionante cesura do nascimento nos faz crer. Quase cinquenta anos depois, Bion retoma este ponto em seu artigo Cesura, enfatizando que o analista não se deve ocupar tanto nem da transferência nem da contratransferência, mas sim da "ferência", daquilo que é sempre levado e trazido, seja de um lugar para outro seja de um tempo para outro. Quase que ao mesmo tempo da escrita de "Inibição, Sintoma e Angústia", em 1923, o poeta russo Ossip Mandelstam escrevia "Meu século", falando da fratura e da continuidade existentes entre um século e outro. Traduzido por Haroldo de Campos como "A era" começa o poema: "Minha era, minha fera, quem ousa, olhando nos teus olhos, com sangue, colar a coluna de tuas vértebras?", terminando dizendo "Era, ex pantera flexível, que volve para trás, riso absurdo, e descobre dura e dócil, na meada dos rastros, as pegadas de seus próprios passos". Este poema é retomado por Giorgio Agamben no final dos anos noventa do século passado em seu importante texto "O que é o contemporâneo?", e aproximando-o das descobertas a respeito da luz visível ainda por nós mas proveniente de estrelas mortas há milhões de anos, faz preciosas considerações a respeito daquilo que conseguimos enxergar, convocando-nos a observar, não o brilho, mas a escuridão do momento presente. Freud já havia dito algo semelhante a Lou Andreas Salomé a propósito da atitude psicanalítica.

3.

Não havia também ele, dez anos antes de Mandelstam, seguindo o rastro da humanidade, colado com o sangue de uma fera, o Pai primevo, a fratura originária, aquela que separa a era da natureza da era da cultura, a animalidade da humanidade? No início, diz ele em "Totem e tabu", o primeiro pensamento foi o ato exercido pela irmandade, o assassinato do pai primevo. $\mathrm{O}$ que nos leva a pensar que a reunião dos irmãos estabeleceu a primeira cadeia sináptica, cada um deles funcionando como aquilo que hoje chamamos de neurônio. $\mathrm{O}$ primeiro Ego, por assim dizer, foi, portanto, grupal. É dessa ruptura com uma ordem estabelecida que nascem em sincronia, segundo Freud, o humano e a cultura. A cena se transforma. Há, a partir daí, de um lado a natureza, de outro a cultura. O caminho percorrido por cada um dos irmãos parricidas se inicia com a devoração do corpo do animal primevo. Mas a cada um deles uma parte específica, diferente. E o animal primevo -a fera daquela erase transformou em canguru, em leão, em serpente e assim por diante. Cada um deles originando um grupo, uma polis, uma cidade. 
4.

Se o primeiro ego, o primeiro sujeito, foi grupal, há que se seguir o rastro do percurso feito pelo homem em direção à individuação. O que ele se propõe a fazer, de algum modo, em seu texto "Psicologia de Grupo e Análise do Ego". Individuação esta que não ocorre fora da experiência de pânico. É sempre perigosa a fratura, a cesura entre uma cena e outra. O modelo é aquele em que um grupo de pessoas se encontra em uma sala de "concerto" e é ouvido um grito de "fogo!" que imediatamente ocasiona uma dispersão, uma desestruturação do status quo. O campo se fratura instaurando o pânico e a individualidade irrompe com toda a força. Os conceitos de Fabio Herrmann de campo transferencial, ruptura de campo e vórtice, nos ajudam enormemente a pensar essas questões, seja num diapasão intrapsíquico ou grupal.

5.

Todo Ego se estrutura dentro e a partir de um campo transferencial específico que ao se romper convoca tanto o grupo como cada um de seus componentes a uma nova solução, a um novo rearranjo que pode ser uma volta ao estado anterior, regredido, extemporâneo, por assim dizer, deixando evidente a continuidade existente entre os campos pré e pós-cesura. Não é para isso que os conceitos de pulsão e o de superego conforme elaborados na teoria estrutural freudiana apontam? Não é o superego o vestígio, a inscrição mesma das pegadas do percurso feito pela espécie desde sua origem até o presente? Não são as pulsões a expressão da animalidade que persiste em cada um de nós, indivíduos civilizados habitantes de uma metrópole do século XXI?

6.

Diferentemente da pedra que é "sem mundo", diferentemente dos animais e das plantas que são "pobres em mundo", nós humanos somos "formadores de mundo", segundo Heidegger. Para ele, pobreza em mundo significa que o animal está encerrado em um ciclo vital do qual não há saída possível, sua linguagem se repetindo indefinidamente. O humano, por sua vez, é um formador de mundo. O que quer dizer que o mundo por cada um de nós formado pode ser mais rico ou mais pobre, dependendo do desenvolvimento ou não de uma linguagem capaz de infinitas combinações e modulações expressivas. Diferentemente do animal que está colado ao seu mundo há, por assim dizer, uma fratura, uma cesura, um distanciamento maior do humano com o seu mundo o que lhe permite um détour próprio entre o nascimento e a morte. Mas como toda fratura, toda cesura pressupõe sempre uma continuidade não é incomum que 
o ser humano também se aprisione dentro de um mundo por ele criado. Uma acomodação, poderíamos dizer, ou um deixar-se capturar por um recorte de mundo criado por seu grupo de pertinência. Uma compulsão à repetição, nas palavras de Freud. O terror ao desconhecido que impede o aprender com a experiência, nas palavras de Bion. Um aprisionamento em um determinado campo transferencial, nas palavras de Herrmann. A incapacidade de perceber a escuridão do presente, deixando-se ofuscar pelo brilho e pela luminosidade que provem de estrelas já mortas, nas palavras de Agamben.

\section{7.}

A fratura ocasionada por Freud no pensamento ocidental foi estruturante de pelo menos um novo campo, o psicanalítico. Mais de cem anos depois da estruturação desse campo não há como negar a força de atração gravitacional que sua voz tem exercido em seus seguidores, nós todos psicanalistas. Mesmo o surgimento de novos desenvolvimentos ou "novas escolas" tem sempre ecoado, em grau maior ou menor, a voz do fundador. Entretanto, não podemos dizer que se soadas em uníssono a resultante seria um concerto agradável aos nossos ouvidos mas sim em algo mais próximo de uma cacofonia, um ruído confuso como não é raro acontecer em discussões entre psicanalistas. Ou, no caso de conversa entre seguidores fanáticos de uma ou outra escola, a musicalidade autoral se perde, dando lugar a um estereótipo aborrecido e esterilizante que contrasta sempre com a palavra viva e indagadora de cada novo paciente. Pois a musicalidade presente no pensamento autoral se perde quando sua perspectiva própria sobre o humano, seus conceitos, é reificada e fetichizada, tornandose apenas letra morta. Ou, fazendo uso da metáfora de Agamben para o contemporâneo, é uma luminosidade proveniente de estrelas já mortas. Muitos de nossos conceitos são ainda iluminadores, outros servem apenas para impedir a visão da obscuridade do presente. Alguns deles não foram ainda apreendidos em toda sua extensão pois ganham nova amplitude, novas ressonâncias se focados em novo contexto histórico.

\section{8.}

Tomemos como exemplo um de nossos conceitos mais básicos, o do complexo de Édipo. Estruturado por Freud, foi posteriormente estendido por Klein ao leva-lo para os inícios da vida mental e ampliado por Bion que enfatizou seu aspecto oracular, na figura de Tirésias. Porém sempre restrito ao contexto familiar, pai-mãe-filho/bebê. A clínica contemporânea nos convoca inexoravelmente a expandi-lo para além da casa familiar, levá-lo do oikos para a 
polis. Não há como desconsiderar mais a que a esfinge se situa às portas de Tebas, i é, às portas da cidade, que o assassinato do pai se deu na encruzilhada de duas estradas e que Édipo era rei. Ao deixar de considerar o elemento político presente e estruturante da tragédia de Sófocles, dando ênfase ao nome familiar -Édipo- Freud deixou de lado o fato de que toda família está inserida em um grupo, em uma polis, fato fundamental na estruturação de toda e qualquer identidade. A tragédia passional envolvendo pai-mãe-filho ganha uma nova dimensão ao se considerar pai/rei e filho/rei. As fronteiras que separam o familiar do político se mostram muito mais frágeis. Não é para isto que nos convoca a clínica contemporânea, na qual a lei do Pai se mostra sombreada, esmaecida pela nova e fortíssima voz midiática?

\section{9.}

Luciano Floridi, professor de filosofia da informação em Oxford, fala em seu último livro de quatro revoluções estruturantes do pensamento ocidental na compreensão do eu e do mundo. A primeira delas ocorrida em 1543 com a publicação de Sobre a Revolução dos Corpos Celestes, por Copérnico que com sua cosmologia heliocêntrica deslocou para sempre a Terra do centro do universo, levando-nos a reconsiderar a nossa posição e nosso papel diante dele. A segunda, quando da publicação por Charles Darwin do seu A Origem das Espécies, em 1859, que deslocou o homem do centro do reino biológico. A terceira revolução se deu, segundo ele, quando da publicação da Interpretação dos Sonhos de Freud, que feriu de morte o racionalismo humano. Mas de algum modo, o pensamento ainda era exclusivo do homem. Até que Alan Turing, com seus trabalhos sobre a informática e a inteligência artificial," vem mostrar que nós, humanos somos organismos informacionais, conectados reciprocamente e parte de um ambiente informacional -a infosfera- que dividimos com outros agentes informacionais, naturais e artificiais que processam informações de modo lógico e autônomo". Este é o momento da quarta revolução. Este é o contemporâneo. A última geração nascida dentro de um referencial de fronteiras, dentro e fora, on e off, foi aquela dos anos noventa do século passado. Segundo Floridi, a partir daí, não faz mais sentido para esta geração em se falar de online e offline, pois o mundo está sempre conectado. Para significar este novo estado, esta nova fratura, ele cria o conceito de on life, isto é, o novo sujeito se configura a partir de um outro paradigma, no qual estar on line e off line deixa de fazer sentido, emergindo a experiência on life, com consequências significativas e ainda imprevisíveis na estruturação da identidade.

10. 
Milhares de anos depois do assassinato do Pai primevo e da emergência do humano e da cultura, uma nova cadeia sináptica é criada através da interligação de mais de sete bilhões de seres humanos. Não há como desconsiderar o impacto que essa imensa quantidade de vozes em uníssono provoca na estruturação desse, por assim dizer, novo sujeito nascido neste novo século, no qual o lá é também o aqui, e o agora está sempre desatualizado. Se a construção freudiana a respeito da origem do homem e da cultura está correta- um pequeno grupo de irmãos instituindo um novo paradigma- o que pensar a respeito de bilhões de humanos conectados em todo o planeta? Não há como desconsiderar seus efeitos na ruptura de uma ordem, de um paradigma.

11.

Afonso, jovem de trinta anos, apresentou-se como sendo de outra cidade, alocado agora em SP por motivos profissionais, e sofrendo muito com sua fobia de elevadores e suas crises de pânico no meio de multidões e do tráfego. Sintomas, segundo ele, de ordem genética pois a maioria dos membros de sua família também os apresentava. Seu terror em ficar aprisionado numa eventual pane do elevador apinhado de gente o levava a subir vinte andares pelas escadas de seu trabalho e contrastava com o fato de sentir-se absolutamente cômodo e à vontade dentro dos aviões que, também por motivos profissionais, tomava para viagens nacionais e internacionais. Na verdade, era onde se sentia melhor, onde "se desligava de tudo". Sua casa não era mais que um dormitório quando estava em SP, contrastando também com a casa de sua cidade de origem, cheia de problemas com um irmão deficiente e um pai que havia falido há alguns anos. Casa essa cuja venda deveria sanar os problemas econômicos de seu pai e de seu irmão, por ele sustentados desde a morte de sua mãe, há três anos. Estava, por assim dizer, encerrado em um mundo melancolizado e congelado, da mesma forma que se sentia em seu conflituoso relacionamento amoroso, o único que tivera na vida, em razão do seu medo da Aids. Em seus sonhos, estava sempre em hotéis em lugares desconhecidos dentro dos quais estava sempre fugindo de perseguidores anônimos. Restavam-lhe portanto seu trabalho, no qual se destacara precocemente, e suas viagens profissionais nas quais passava por três ou quatro países em dois dias mas "sempre dormindo em hotéis de primeira linha"... Após um ano de análise, começam a surgir os primeiros movimentos significativos de mudança: rupturas e reatamentos de seu namoro, início de uma atividade física com um personal trainer, e alguns sonhos nos quais os cenários eram identificáveis, em geral, a sua casa de origem. Começa também a legitimar sua percepção de que é um profissional bastante competente e considerado, conseguindo separar sua 
"economia", seu sustento, daquela de sua família. Os elevadores continuam um grande problema embora já os tenha dividido entre aqueles que poderia usar e alguns ainda impraticáveis, os de prédios mais antigos. Estabiliza-se por mais um ano nestas condições quando começa a falar sobre o medo de uma viagem que deverá fazer a um país árabe no qual um colega seu havia sido preso em uma viagem anterior. Conseguir ou não o visto passa a ser o tema de uma inteira sessão de análise. Na sessão seguinte, um sonho: estava em um aeroporto e via o avião mas não tinha certeza se seu visto estava em ordem. Conversamos sobre uma mudança que estava ocorrendo, um novo lugar existencial para o qual ele não sabia se tinha passaporte válido. Poucos meses depois, chega em uma sessão após um Carnaval, dizendo que tudo foi abaixo. Não havia conseguido tomar o avião que o levaria para uma viagem. Uma crise de pânico o fizera sair antes do avião decolar. Achava que sua vida estava acabada pois agora não poderia mais trabalhar. Não saíra de seu quarto até vir à análise. Eu apenas sugeri que ele agora tinha embarcado de fato: a mudança havia se dado e se o avião não era mais seu "safe place" era porque havia conseguido um passaporte para um novo lugar, ao contrário do que ele estava pensando. Imediatamente, ele começa a se acalmar e a relatar o que havia passado por sua cabeça durante os dias em que ficara deitado em casa: uma súmula de sua vida, uma autobiografia por assim dizer, com a conclusão de que se continuasse a ser daquele jeito não queria mais continuar vivendo.

12.

Continuando a viver, fez aquilo que chamou de alguns voos testes pois o avião não era mais seu "safe place". Compra, então, seu primeiro apartamento, fato que ocupa muitas de nossas sessões. Um novo lugar existencial se evidencia. E sua mudança está marcada para o final da semana. Na sessão seguinte chega falando da próxima viagem profissional que acabara de ser marcada e na qual deveria fazer reuniões em três países no mesmo dia: Milão, no início da manhã, voando para Paris na hora do almoço para outra reunião e, em seguida, pegando outro avião para Genebra, de onde sairia no dia seguinte para Londres. Agenda não muito diferente de outras que havia relatado no passado e nunca questionada. Diz que é a primeira vez que confronta seu chefe, alongando-se por quase trinta minutos da sessão em seu relato, quando interrompo-o dizendo que me surpreende o fato de não ter feito até então nenhuma referência à mudança para a nova casa, fato tão investido por ele. Ou melhor, não seria o fato de sentirse agora não mais num "hotel”, nem na antiga casa da família, mas estabelecido num lugar por ele construído, aquilo que o estaria levando a poder questionar tantos deslocamentos? 
Tinha um chão, um ponto fixo de observação e assim era capaz de se confrontar com agendas impraticáveis.

13.

Afonso vivia, por um lado, capturado em um mundo melancólico e, por outro, capturado em um mundo corporativo financeiro. Por um lado, a voz imperativa de sua mãe, por outro, as regras inescapáveis ditadas pelo banco. Assim, impedido de ser um "formador de mundo", vivia na pobreza de um passado congelado e de um presente acelerado. Seu Eu apequenado era quase que uma extensão do grupo familiar ou do grupo de inserção profissional. Um "Eu em condomínio", poder-se-ia dizer. A evolução de sua análise que ainda está em andamento tem sido na direção de uma construção de um Eu próprio, sua casa, sendo capaz de se sentir seguro num espaço existencial próprio.

14.

Tarefa análoga se impõe a todos nós analistas praticantes neste início de um novo milênio. Nem nos deixarmos aprisionar no espaço conceitual por nós herdado, nem nos deixarmos capturar ou absorver passivamente pela aceleração constante do mundo contemporâneo, a infosfera, como a batizou Floridi. Nem aprisionar a fala viva de nossos pacientes no mundo conceitual por nós herdado, nem nos deixarmos paralisar pelo desconcerto que ela fatalmente nos traz. Só assim estaremos inseridos na melhor das tradições, a de preservar o fogo e jamais cultuar as cinzas.

\section{Referências}

Agamben, G.- Che cos'è il contemporâneo?

Floridi, L. (2017). La quarta rivoluzione. Raffaello Cortina Editore. Milano. 